\title{
Gestational Hypertension and Organophosphorus Pesticide Exposure: A Cross-Sectional Study
}

\author{
Caterina Ledda, ${ }^{1}$ Maria Fiore, ${ }^{1}$ Lory Santarelli, ${ }^{2}$ Massimo Bracci, ${ }^{2}$ Giuseppe Mascali, ${ }^{3}$ \\ Maria Grazia D'Agati, ${ }^{1}$ Alfredo Busà, ${ }^{4}$ Margherita Ferrante, ${ }^{1}$ and Venerando Rapisarda ${ }^{5}$ \\ ${ }^{1}$ Hygiene and Public Health, Department of G.F. Ingrassia, University of Catania, Via Santa Sofia 87, 95123 Catania, Italy \\ ${ }^{2}$ Occupational Medicine, Department of Clinical and Molecular Science, Polytechnic University of Marche, Via Tronto 10/A, \\ 60100 Ancona, Italy \\ ${ }^{3}$ Division of Clinical Pathology, Hospital of Taormina, ASP Messina, C/da Sirina, 98039 Taormina, Italy \\ ${ }^{4}$ Division of Cardiology, Hospital of Lentini, ASP Siracusa, C/da Colle Roggio, 96016 Lentini, Italy \\ ${ }^{5}$ Occupational Medicine, "Policlinico-Vittorio Emanuele” University Hospital, University of Catania, Via Santa Sofia 78, \\ 95123 Catania, Italy \\ Correspondence should be addressed to Caterina Ledda; cledda@unict.it
}

Received 18 November 2014; Revised 22 January 2015; Accepted 27 May 2015

Academic Editor: Sunil Kumar

Copyright (C) 2015 Caterina Ledda et al. This is an open access article distributed under the Creative Commons Attribution License, which permits unrestricted use, distribution, and reproduction in any medium, provided the original work is properly cited.

\begin{abstract}
Hypertension is the most common medical problem encountered during pregnancy, complicating 2-3\% of pregnancies. High blood pressure (BP) with diastolic $\mathrm{BP} \geq 90 \mathrm{~mm} \mathrm{Hg}$ and/or systolic $\mathrm{BP} \geq 140 \mathrm{~mm} \mathrm{Hg}$ arising after week 22 of pregnancy and resolving after delivery is defined as gestational hypertension (GHY). The aim of this cross-sectional study was to investigate whether occupational and/or environmental exposure to organophosphorus (OP) pesticide affects GHY. Women at approximately 22 weeks of gestation were recruited. OP pesticide exposure in the first trimester of pregnancy was classified into four categories: no exposure, indirect exposure, domestic exposure, and occupational exposure. Application of the exclusion criteria left 2203 participants (mean age 30.4 \pm 11.6 years). Data analysis showed that in women with indirect OP pesticide exposure the incidence of GHY was slightly higher than that in the world population, whereas domestic exposure involved a $7 \%$ increase and occupational exposure a $12 \%$ increase. Analysis of the pesticides used by participants highlighted a possible role for malathion and diazinon (adjusted OR 1.09 and 1.14, resp.). Further investigation of exposed workers and the general population is clearly warranted given the broad diffusion of OP pesticides and their possible public health impact, maybe by including a wider range of health outcomes.
\end{abstract}

\section{Introduction}

Hypertension is the most common medical problem encountered during pregnancy, complicating $2-3 \%$ of pregnancies $[1,2]$. Hypertensive disorders during pregnancy are classified by the Working Group on High Blood Pressure in Pregnancy into four categories: chronic hypertension; preeclampsiaeclampsia; preeclampsia superimposed on chronic hypertension; and gestational hypertension (GHY) $[1,2]$. High blood pressure (BP) with diastolic $\mathrm{BP} \geq 90 \mathrm{~mm} \mathrm{Hg}$ and/or systolic $\mathrm{BP} \geq 140 \mathrm{~mm} \mathrm{Hg}$ arising after week 20 of pregnancy and resolving after delivery is defined as GHY $[1,2]$.
Risk factors include first pregnancy, obesity, high maternal age, preexisting diabetes, renal disease, hypertension, and chronic autoimmune disease [3-7].

Maternal exposure to chemicals has seldom been investigated in relation to hypertensive disorders during pregnancy. Some studies have suggested that lead, cadmium and other metals or elements [8-10], organic solvents [11], air pollution [12-15], and pesticides [16-19] may increase the risk of hypertensive disorders. The effects of organophosphorus (OP) pesticides on hypertension have been investigated in vivo, in the general population and in workers [20-27], but not during pregnancy. 
The aim of this cross-sectional study was to investigate whether occupational and environmental exposure to $\mathrm{OP}$ pesticides affects GHY.

\section{Materials and Methods}

2.1. Subject and Pesticide Exposure. Women at approximately 22 weeks of gestation were recruited by general practitioners or occupational physicians from 2007 to 2013. The study took place in Sicily. Individuals referred by the occupational physicians were recruited to the study by posted study information or direct physician contact. No restriction was placed on the number of participants.

The study protocol was approved by the Catania University Hospital Ethical Committee, and informed consent forms were signed by all participants prior to enrolment.

The enrolment procedure involved a detailed medical history; a structured questionnaire investigating environmental and occupational risk was administered by trained interviewers to gather accurate data on demographics, health habits, and pesticide and other chemical exposures. In order to make a correct classification, specific questions were formulated regarding exclusive $\mathrm{OP}$ pesticides. Exposure in the first trimester of pregnancy was classified into four categories: no exposure (women reporting no exposure); indirect exposure (from planting, pruning, weeding, picking, or harvesting); domestic exposure (from pesticide use in the garden or in the house); occupational exposure (from work with pesticides).

The body mass index (BMI) was calculated based on prepregnancy weight referred by each subject.

For BP measurements, using a validated 907 automated digital oscillometric sphygmomanometer (Omron Healthcare Europe B.V., Hoofddorp, Netherlands), participants sat on chairs with a back support. After 20 min acclimatization (room temperature $23.0 \pm 2.0^{\circ} \mathrm{C}$ ) a medical doctor placed a cuff around the left upper arm, which rested at the level of the heart, with the stethoscope over the brachial artery pulsation. The mean value of three readings taken over a $20 \mathrm{~m}$ interval was recorded.

Participants were considered to have GHY if they had systolic $\mathrm{BP} \geq 140 \mathrm{~mm} \mathrm{Hg}$ and/or diastolic $\mathrm{BP} \geq 90 \mathrm{mmHg}$.

Women with hypertension before pregnancy, anaemia, toxaemia of pregnancy, kidney or heart disease, diabetes, urinary tract infection, metabolic disorders, antiphospholipid antibody syndrome, multiple pregnancies, a BMI $<19$ or $>$ $35 \mathrm{~kg} / \mathrm{m}^{2}$, and those reporting complications during earlier pregnancies and/or deliveries were excluded.

2.2. Statistical Analysis. Data were analyzed using SPSS 20.0 software for Windows (SPSS Inc., Chicago, IL, USA). Mean standard deviation (SD) and percentages were used to evaluate descriptive statistics.

Odds ratios (ORs) and 95\% confidence intervals (95\% CI) for the occurrence of GHY as a function of OP exposure were estimated under conditional logistic regression model. Data were adjusted for maternal age, smoking, alcohol, and BMI. A value of $p<0.05$ was considered significant.

\section{Results and Discussion}

Of the 2788 pregnant women referred to the study from 2007 to 2013, 157 refused to participate; 107 reported simultaneous exposure to several classes or other types of pesticide; and 321 met one or more other exclusion criteria, leaving 2203 participants whose mean age was $30.4 \pm 11.6$ years. $\mathrm{BP}$ of overall women average was $123 \pm 14.1 \mathrm{~mm} \mathrm{Hg}$ and $82 \pm 11.8 \mathrm{~mm} \mathrm{Hg}$, for systolic and diastolic, respectively. The only OP used by our population observed are chlorpyrifos, diazinon, malathion, and parathion.

Their exposure data are reported in Table 1.

Hypertension in pregnancy is very common. It complicates almost $10 \%$ of all pregnancies and contributes much to maternal and perinatal morbidity and mortality [2]; our data analysis showed that domestic exposure involved a $7 \%$ increase and occupational exposure a 12\% increase. Analysis of the OP pesticides used by participants highlighted a possible role for malathion and diazinon for GHY (Table 2).

Neither malathion nor diazinon appear to have been investigated in recent studies of the general population or of exposed workers. Earlier studies showed that cardiovascular signs due to acute oral exposure to high diazinon doses include tachycardia [28, 29], hypertension [30, 31], and bradycardia [29, 31].

As regards diazinon, its toxicity is chiefly due to central and peripheral nervous system acetylcholinesterase (AChE) inhibition. AChE is responsible for terminating the action of the neurotransmitter acetylcholine (ACh) at pre- and postsynaptic nerve endings and neuromuscular junctions by hydrolyzing it. AChE inhibition by diazinon is exerted via formation of a stable phosphorylated complex that is incapable of removing $\mathrm{ACh}$. The resulting $\mathrm{ACh}$ accumulation at these sites involves constant or anyway excessive cholinergic fibre stimulation at the level of postganglionic parasympathetic nerve endings, neuromuscular junctions, skeletal muscle, as well as CNS cells, giving rise to hyperpolarization and receptor desensitization. Such effects are exerted on end organs innervated by fibres in the postganglionic parasympathetic nerves (e.g., heart, blood vessels, and secretory glands) and induce muscarinic effects that manifest as "miosis, excessive gland secretion (salivation, lacrimation, rhinitis), nausea, urinary incontinence, vomiting, abdominal pain, diarrhea, bronchoconstriction or bronchospasm, increased bronchosecretion, vasodilation, bradycardia, and hypotension" [32], whereas ACh build-up at the level of skeletal muscle junctions and sympathetic preganglionic nerve endings gives rise to nicotinic effects that manifest as "muscle fasciculation, weakness, mydriasis, tachycardia, and hypertension" [32].

Cardiovascular effects were noted in nearly all reported cases of malathion poisoning [33-36]. Admission signs and symptoms generally included bradycardia and low BP, as in vagal stimulation. Several patients also had atrioventricular conduction disturbances within a few days of pesticide ingestion $[33,34]$. The doses ingested in these cases ranged from 214 to $2,117 \mathrm{mg} / \mathrm{kg}$. In contrast, Choi et al. [37] reported abnormal emergency room electrocardiogram and chest Xrays in a woman who ingested approximately $1.071 \mathrm{mg} / \mathrm{kg}$. Tachycardia may be the result of cholinergic stimulation 
TABLE 1: Characteristics of participants.

\begin{tabular}{|c|c|c|c|c|c|}
\hline & No exposure & Indirect exposure & Domestic exposure & Occupational exposure & Total \\
\hline Subject $n(\%)$ & $\begin{array}{c}582 \\
\text { (26\% of total) }\end{array}$ & $\begin{array}{c}534 \\
(24 \% \text { of total })\end{array}$ & $\begin{array}{c}613 \\
(28 \% \text { of total })\end{array}$ & $\begin{array}{c}474 \\
(22 \% \text { of total })\end{array}$ & 2203 \\
\hline \multicolumn{6}{|l|}{ Age } \\
\hline $18-22 y$ & $98(17 \%)$ & $94(18 \%)$ & $78(13 \%)$ & $69(15 \%)$ & $339(15 \%)$ \\
\hline $23-27 y$ & $127(22 \%)$ & $102(19 \%)$ & $114(18 \%)$ & $63(13 \%)$ & $406(18 \%)$ \\
\hline $28-32 y$ & $136(23 \%)$ & $115(21 \%)$ & $145(24 \%)$ & $103(22 \%)$ & $499(23 \%)$ \\
\hline $33-37 y$ & $120(21 \%)$ & $121(23 \%)$ & $153(25 \%)$ & $128(27 \%)$ & $522(24 \%)$ \\
\hline $38-42 y$ & $101(17 \%)$ & $102(19 \%)$ & $123(20 \%)$ & $111(23 \%)$ & $437(20 \%)$ \\
\hline \multicolumn{6}{|l|}{ Education } \\
\hline Secondary & $196(34 \%)$ & $124(23 \%)$ & $135(22 \%)$ & $273(58 \%)$ & $728(33 \%)$ \\
\hline High school diploma & $286(49 \%)$ & $286(54 \%)$ & $236(39 \%)$ & $147(31 \%)$ & $955(43 \%)$ \\
\hline Degree & $100(17 \%)$ & $124(23 \%)$ & $242(39 \%)$ & $54(11 \%)$ & $520(24 \%)$ \\
\hline \multicolumn{6}{|l|}{ Body mass index } \\
\hline$<24 \mathrm{~kg} / \mathrm{m}^{2}$ & $185(32 \%)$ & $167(31 \%)$ & $126(20 \%)$ & $102(22 \%)$ & $580(26 \%)$ \\
\hline $25-30 \mathrm{~kg} / \mathrm{m}^{2}$ & $265(45 \%)$ & $243(46 \%)$ & $274(45 \%)$ & $275(58 \%)$ & $1057(48 \%)$ \\
\hline$>30 \mathrm{~kg} / \mathrm{m}^{2}$ & $132(23 \%)$ & $124(23 \%)$ & $213(35 \%)$ & $97(20 \%)$ & $566(26 \%)$ \\
\hline \multicolumn{6}{|l|}{ Smoking habits } \\
\hline No & $247(42 \%)$ & $223(42 \%)$ & $278(45 \%)$ & $264(56 \%)$ & $1012(46 \%)$ \\
\hline Until she knew of her pregnancy & $272(47 \%)$ & $264(49 \%)$ & $276(45 \%)$ & $136(29 \%)$ & $948(43 \%)$ \\
\hline Yes, during pregnancy & $63(11 \%)$ & $47(9 \%)$ & $59(10 \%)$ & $74(15 \%)$ & $243(11 \%)$ \\
\hline \multicolumn{6}{|l|}{ Alcohol drinking habits } \\
\hline No & $241(41 \%)$ & $238(45 \%)$ & $247(40 \%)$ & $172(36 \%)$ & $898(41 \%)$ \\
\hline Until she knew of her pregnancy & $243(42 \%)$ & $214(40 \%)$ & $269(44 \%)$ & $216(46 \%)$ & $942(43 \%)$ \\
\hline Yes, during the pregnancy & $98(17 \%)$ & $82(15 \%)$ & $97(16 \%)$ & $86(18 \%)$ & $363(16 \%)$ \\
\hline Gestational hypertension & $26(4 \%)$ & $33(6 \%)$ & $41(7 \%)$ & $55(12 \%)$ & $155(7 \%)$ \\
\hline
\end{tabular}

TABLE 2: Association between use of organophosphorus pesticides and gestational hypertension.

\begin{tabular}{lcccc}
\hline & \multicolumn{4}{c}{ Gestational hypertension } \\
& $n$ & \% exp & aOR & $95 \%$ CI \\
\hline No exposure & 26 & - & 1.00 \\
Chlorpyrifos & 25 & 20 & 1.03 & $0.86-1.08$ \\
Diazinon & 30 & 23 & $1.09^{*}$ & $1.03-1.16$ \\
Malathion & 48 & 37 & $1.14^{*}$ & $1.08-1.19$ \\
Parathion & 26 & 20 & 1.02 & $0.78-1.19$ \\
\hline
\end{tabular}

$\% \exp =$ proportion of participants with gestational hypertension actually exposed to the agent.

$\mathrm{aOR}=$ effect estimates adjusted for age, smoking and alcohol drinking habits, and BMI.

${ }^{*} p$ value $<0.05$

of parasympathetic and sympathetic autonomic ganglia. Administration of gavage doses of $390 \mathrm{mg} \mathrm{kg} /$ day (unspecified purity) for 1-2 weeks caused focal haemorrhage in the heart of rats [38]. A single gavage dose of $1.950 \mathrm{mg} / \mathrm{kg}(95 \%$ pure), the only malathion dose tested, caused congestion and haemorrhage in the heart of male Wistar rats 2 days after dosing; females were not tested [39].
Based on our findings and the literature data correct exposure information is clearly required for OP pesticide use by pregnant women, whatever the exposure level. In fact two studies of other classes of pesticides confirm that the agent is passed from mother to fetus $[17,40]$. In addition pesticides are known to play a role in inflammation processes $[41,42]$.

\section{Conclusions}

This study suggests that the OP pesticides malathion and diazinon may be associated with GHY, although the literature reports limited evidence for this notion. Further investigation of exposed workers and the general population is clearly warranted given the broad diffusion of OP pesticides and their possible public health impact, maybe by including a wider range of health outcomes. The level of exposure should also be investigated in greater detail via biological indicators of damage and inflammation processes.

\section{Conflict of Interests}

The authors affirm that they have no financial affiliation or involvement with any commercial organization with direct 
financial interest in the subject or materials discussed in this paper and deny any conflict of interests related to this study.

\section{References}

[1] J. M. Roberts and K. Y. Lain, "Recent insights into the pathogenesis of pre-eclampsia," Placenta, vol. 23, no. 5, pp. 359-372, 2002.

[2] J. M. Roberts, G. Pearson, J. Cutler, and M. Lindheimer, "Summary of the NHLBI working group on research on hypertension during pregnancy," Hypertension, vol. 41, no. 3, pp. 437-445, 2003.

[3] P.-Y. Ancel, S. Marret, B. Larroque et al., "Are maternal hypertension and small-for-gestational age risk factors for severe intraventricular hemorrhage and cystic periventricular leukomalacia? Results of the EPIPAGE cohort study," American Journal of Obstetrics \& Gynecology, vol. 193, no. 1, pp. 178-184, 2005.

[4] A. Ohkuchi, R. Iwasaki, H. Suzuki et al., "Normal and highnormal blood pressure but not body mass index, are risk factors for the subsequent occurrence of both preeclampsia and gestational hypertension: a retrospective cohort study," Hypertension Research, vol. 29, no. 3, pp. 161-167, 2006.

[5] C. L. Robbins, P. M. Dietz, J. Bombard, and A. L. Valderrama, "Gestational hypertension: a neglected cardiovascular disease risk marker," American Journal of Obstetrics and Gynecology, vol. 204, no. 4, pp. 336.el-336.e9, 2011.

[6] H. S. Ros, S. Cnattingius, and L. Lipworth, "Comparison of risk factors for preeclampsia and gestational hypertension in a population-based cohort study," American Journal of Epidemiology, vol. 147, no. 11, pp. 1062-1070, 1998.

[7] L. Yang, W. Zhang, L. Zhang et al., "Gestational hypertension risk evaluation based on epidemiological, biochemical, and hemodynamic factors," Clinical and Experimental Obstetrics and Gynecology, vol. 40, no. 1, pp. 61-65, 2013.

[8] E. Casanueva and F. E. Viteri, "Iron and oxidative stress in pregnancy," Journal of Nutrition, vol. 133, no. 5, pp. 1700S-1708S, 2003.

[9] G. Huel, C. Boudene, and M. A. Ibrahim, "Cadmium and lead content of maternal and newborn hair: relationship to parity, birth weight, and hypertension," Archives of Environmental Health, vol. 36, no. 5, pp. 221-227, 1981.

[10] J. Magri, M. Sammut, and C. Savona-Ventura, "Lead and other metals in gestational hypertension," International Journal of Gynecology and Obstetrics, vol. 83, no. 1, pp. 29-36, 2003.

[11] J. B. Hewitt and L. Tellier, "Risk of adverse outcomes in pregnant women exposed to solvents," Journal of Obstetric, Gynecologic, and Neonatal Nursing, vol. 27, no. 5, pp. 521-531, 1998.

[12] W. A. Jedrychowski, F. P. Perera, U. Maugeri et al., "Prohypertensive effect of gestational personal exposure to fine particulate matter. Prospective cohort study in non-smoking and nonobese pregnant women," Cardiovascular Toxicology, vol. 12, no. 3, pp. 216-225, 2012.

[13] P.-C. Lee, J. M. Roberts, J. M. Catov, E. O. Talbott, and B. Ritz, "First trimester exposure to ambient air pollution, pregnancy complications and adverse birth outcomes in Allegheny County, PA," Maternal and Child Health Journal, vol. 17, no. 3, pp. 545-555, 2013.

[14] L. C. Vinikoor-Imler, S. C. Gray, S. E. Edwards, and M. L. Miranda, "The effects of exposure to particulate matter and neighbourhood deprivation on gestational hypertension,"
Paediatric and Perinatal Epidemiology, vol. 26, no. 2, pp. 91-100, 2012.

[15] X. Xu, H. Hu, S. Ha, and J. Roth, "Ambient air pollution and hypertensive disorder of pregnancy," Journal of Epidemiology and Community Health, vol. 68, no. 1, pp. 13-20, 2014.

[16] H. Patayová, S. Wimmerová, K. Lancz et al., "Anthropometric, socioeconomic, and maternal health determinants of placental transfer of organochlorine compounds," Environmental Science and Pollution Research, vol. 20, no. 12, pp. 8557-8566, 2013.

[17] N. M. Samra and A. A. Selim, "Organochlorine pesticides concentrations in maternal serum and their effects on umbilical cord serum pesticides concentrations, neonatal birth weight and gestational age," Australian Journal of Basic and Applied Sciences, vol. 3, no. 3, pp. 1972-1983, 2009.

[18] T. M. Saldana, O. Basso, D. D. Baírd et al., "Pesticide exposure and hypertensive disorders during pregnancy," Environmental Health Perspectives, vol. 117, no. 9, pp. 1393-1396, 2009.

[19] J. Flocks, M. Kelley, J. Economos, and L. McCauley, "Female farmworkers' perceptions of pesticide exposure and pregnancy health," Journal of Immigrant and Minority Health, vol. 14, no. 4, pp. 626-632, 2012.

[20] A. Bataillard, F. Sannajust, D. Yoccoz, G. Blanchet, H. SentenacRoumanou, and J. Sassard, "Cardiovascular consequences of organophosphorus poisoning and of antidotes in conscious unrestrained rats," Pharmacology and Toxicology, vol. 67, no. 1, pp. 27-35, 1990.

[21] K. K. Kwang, M. J. Quon, J. L. Sang et al., "Efonidipine simultaneously improves blood pressure, endothelial function, and metabolic parameters in nondiabetic patients with hypertension," Diabetes Care, vol. 30, no. 6, pp. 1605-1607, 2007.

[22] M. Liu, L. Gu, M. S. Sulkin et al., "Mitochondrial dysfunction causing cardiac sodium channel downregulation in cardiomyopathy," Journal of Molecular and Cellular Cardiology, vol. 54, no. 1, pp. 25-34, 2013.

[23] S. Singh, "Organophosphorus poisoning: an evidence based approach," Medical Journal Armed Forces India, vol. 60, no. 1, pp. 2-4, 2004.

[24] I. M. Subbiah, D. J. Lenihan, and A. M. Tsimberidou, "Cardiovascular toxicity profiles of vascular-disrupting agents," Oncologist, vol. 16, no. 8, pp. 1120-1130, 2011.

[25] T. Tanaka, T. Tsutamoto, H. Sakai, M. Fujii, T. Yamamoto, and M. Horie, "Comparison of the effects of efonidipine and amlodipine on aldosterone in patients with hypertension," Hypertension Research, vol. 30, no. 8, pp. 691-697, 2007.

[26] S. Thiphom, T. Prapamontol, S. Chantara, A. Mangklabruks, and C. Suphavilai, "A method for measuring cholinesterase activity in human saliva and its application to farmers and consumers," Analytical Methods, vol. 5, no. 18, pp. 4687-4693, 2013.

[27] Y. Watanabe, T. Itoh, H. Shiraishi et al., "Acute effects of a sarin-like organophosphorus agent, bis(isopropyl methyl)phosphonate, on cardiovascular parameters in anaesthetized, artificially ventilated rats," Toxicology and Applied Pharmacology, vol. 272, no. 1, pp. 61-66, 2013.

[28] V. N. Kabrawala, R. M. Shah, and G. G. Oza, "Diazinon poisoning. (A study of 25 cases)," The Indian Practitioner, vol. 18, no. 10, pp. 711-717, 1965.

[29] H. W. Klemmer, E. R. Reichert, W. L. Yauger Jr., and T. J. Haley, "Five cases of intentional ingestion of 25 percent diazinon with treatment and recovery," Clinical Toxicology, vol. 12, no. 4, pp. 435-444, 1978. 
[30] S. G. Balani, S. O. Fernandes, R. H. Lakhani, and V. J. Juthani, "Diazinon poisoning. A report on 100 cases with particular reference to evaluation of treatment," The Journal of the Association of Physicians of India, vol. 16, no. 11, pp. 911-917, 1968.

[31] S. Hata, E. Bernstein, and L. E. Davis, "Atypical ocular bobbing in acute organophosphate poisoning," Archives of Neurology, vol. 43, no. 2, pp. 185-186, 1986.

[32] Agency for Toxic Substances and Disease Registry (ATSDR), Toxicological Profile for Diazinon, U.S. Department of Health and Human Services, Public Health Service, Atlanta, Ga, USA, 2008.

[33] W. J. Crowley Jr. and T. R. Johns, "Accidental malathion poisoning," Archives of Neurology, vol. 14, no. 6, pp. 611-616, 1966.

[34] A. Dive, P. Mahieu, R. van Binst et al., "Unusual manifestations after malathion poisoning," Human \& Experimental Toxicology, vol. 13, no. 4, pp. 271-274, 1994.

[35] A. Jusic and S. Milic, "Neuromuscular synapse testing in two cases of suicidal organophosphorous pesticide poisoning," Archives of Environmental Health, vol. 33, no. 5, pp. 240-243, 1978.

[36] U. Zivot, J. L. Castorena, and J. C. Garriott, "A case of fatal ingestion of malathion," American Journal of Forensic Medicine and Pathology, vol. 14, no. 1, pp. 51-53, 1993.

[37] P. T.-L. Choi, L. G. Quinonez, D. J. Cook, F. Baxter, and L. Whitehead, "The use of glycopyrrolate in a case of intermediate syndrome following acute organophosphate poisoning," Canadian Journal of Anaesthesia, vol. 45, no. 4, pp. 337-340, 1998.

[38] S. Piramanayagam and B. Murali Manohar, "Blood biochemical profile of experimentally induced malathion toxicity in rats," Indian Veterinary Journal, vol. 79, no. 6, pp. 622-623, 2002.

[39] S. Piramanayagam, B. Murali Manohar, and A. Sundararaj, "Pathology of malathion toxicity in rats," Indian Veterinary Journal, vol. 73, no. 7, pp. 734-737, 1996.

[40] E. Sharma, M. Mustafa, R. Pathak et al., "A case control study of gene environmental interaction in fetal growth restriction with special reference to organochlorine pesticides," European Journal of Obstetrics Gynecology and Reproductive Biology, vol. 161, no. 2, pp. 163-169, 2012.

[41] C. Costa, V. Rapisarda, S. Catania, C. Di Nola, C. Ledda, and C. Fenga, "Cytokine patterns in greenhouse workers occupationally exposed to $\alpha$-cypermethrin: an observational study," Environmental Toxicology and Pharmacology, vol. 36, no. 3, pp. 796-800, 2013.

[42] E. Corsini, M. Sokooti, C. L. Galli, A. Moretto, and C. Colosio, "Pesticide induced immunotoxicity in humans: a comprehensive review of the existing evidence," Toxicology, vol. 307, pp. 123-135, 2013. 

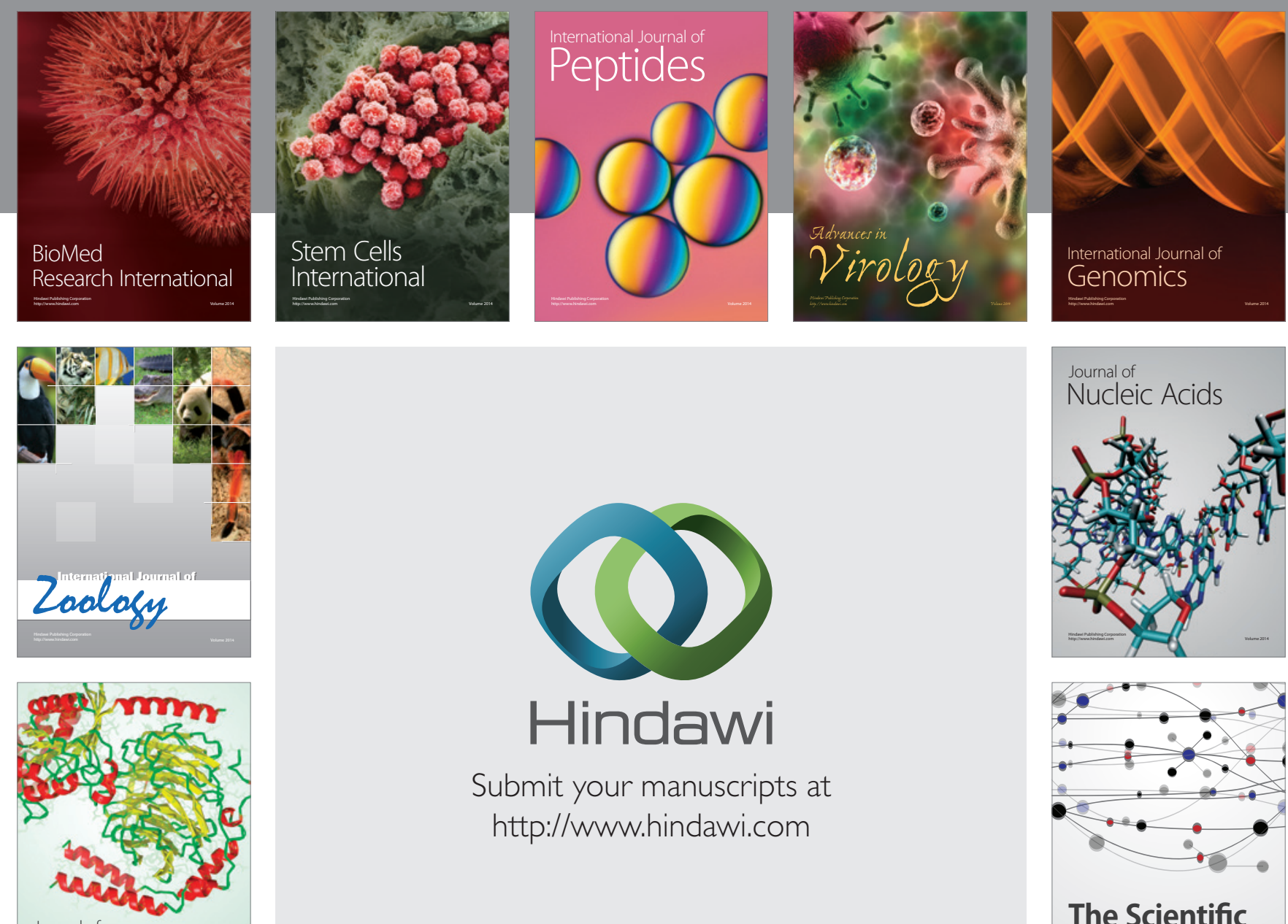

Submit your manuscripts at

http://www.hindawi.com

Journal of
Signal Transduction
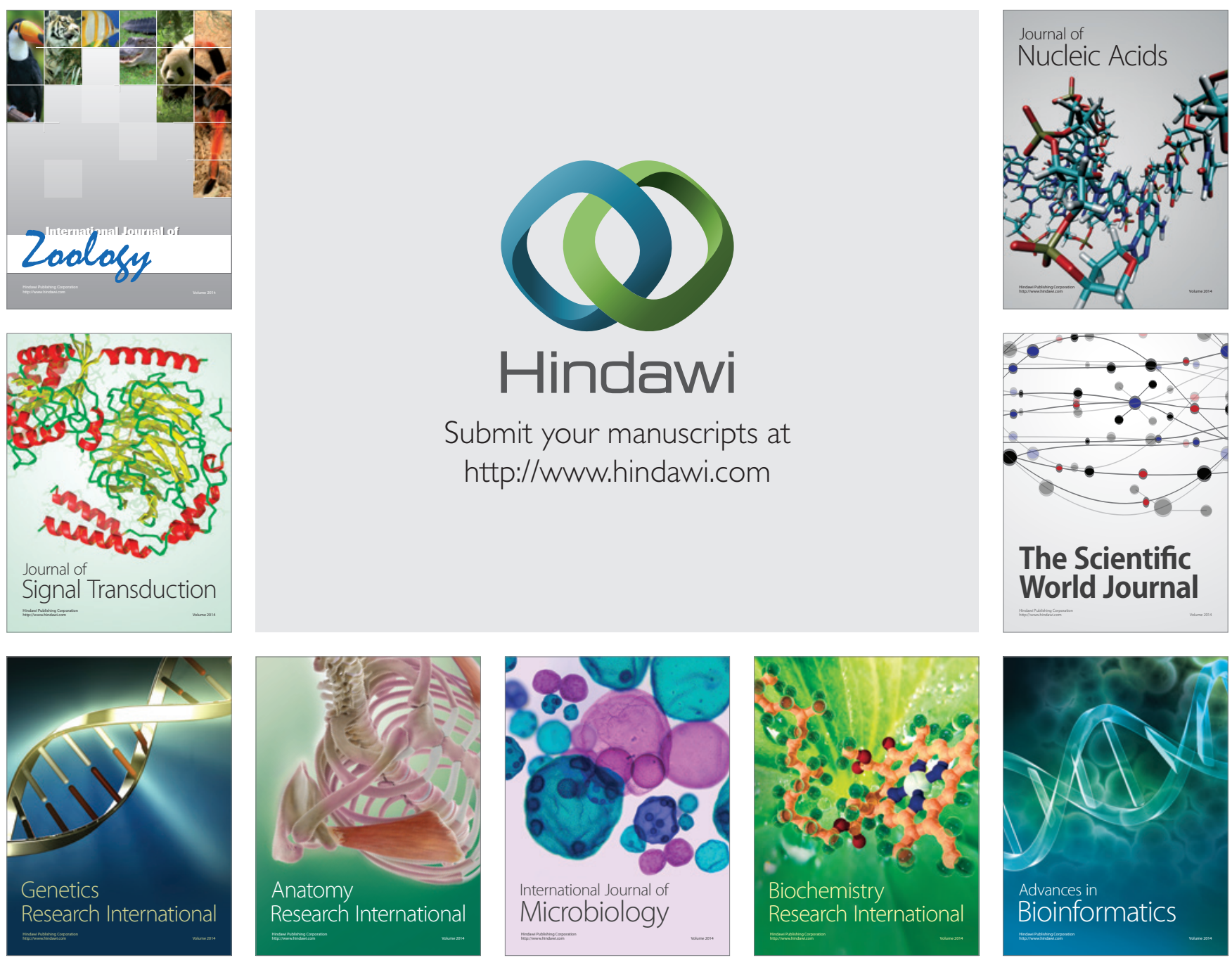

The Scientific World Journal
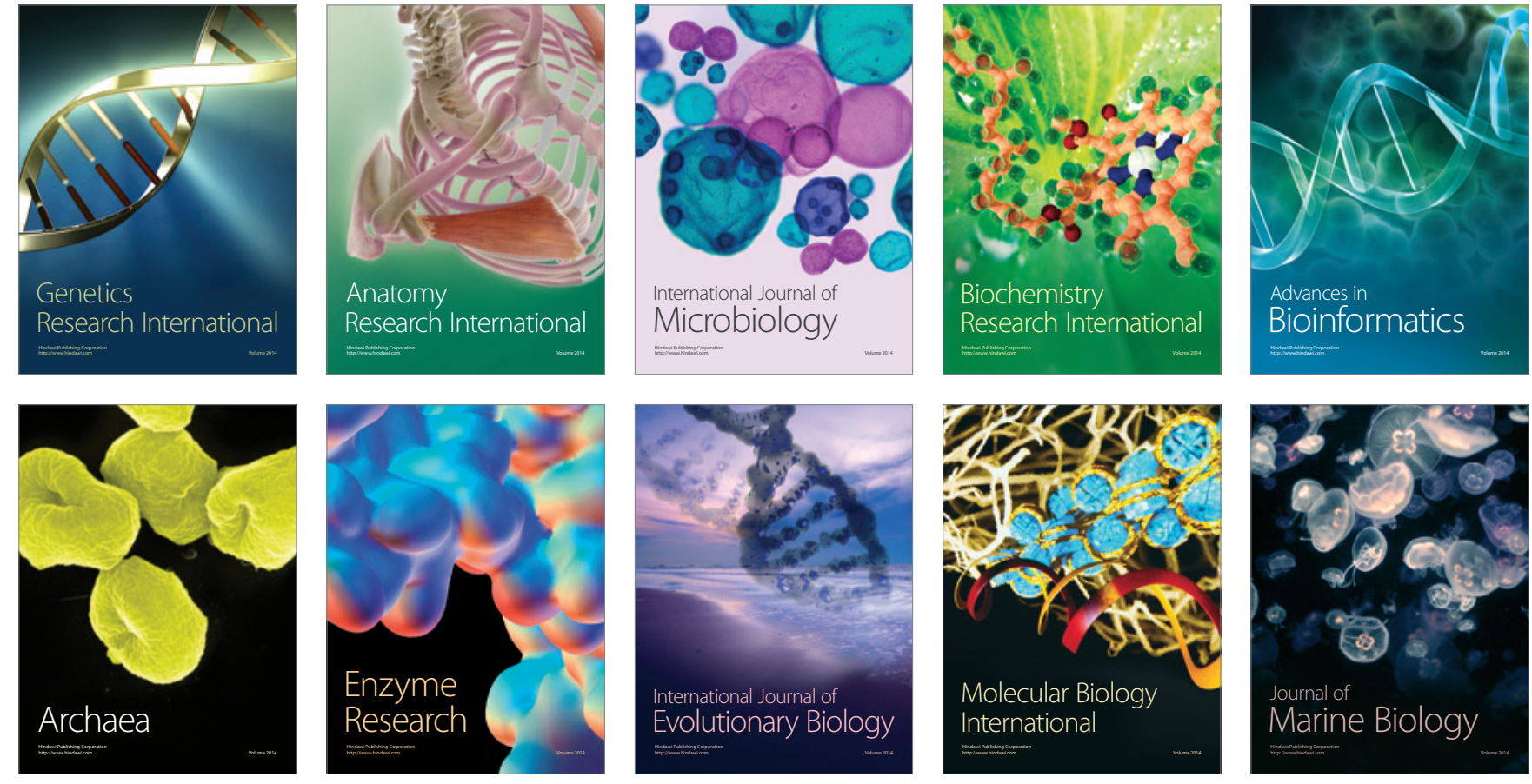